\title{
A 54-year-old woman with chronic lithium toxicity
}

\author{
Jane Kobylianskii MD, Emily Austin MD, Wayne L. Gold MD, Peter E. Wu MD MSc
}

Cite as: CMAJ 2021 August 30;193:E1345-8. doi: 10.1503/cmaj.210725

A 54-year-old woman presented to the emergency department with a 2-day history of altered mental status, weakness and involuntary movements. Her medical history included bipolar I disorder, which had been diagnosed 32 years previously. Her prescribed medications were lithium carbonate $900 \mathrm{mg}$ (sustained-release preparation) orally daily, risperidone $3 \mathrm{mg}$ orally daily, benztropine $1 \mathrm{mg}$ orally daily and lorazepam $0.5 \mathrm{mg}$ orally daily as needed. Her lithium dose had been stable for many years, and there was no history of acute overdose or dosing error. She was not taking any over-thecounter medications or other substances.

On examination the patient was afebrile, her blood pressure was 101/54 mm Hg, and heart rate was 110 beats/min and regular. Her mental status was altered, with a Glasgow Coma Scale score of 10 (E4 V2 M4). She had a coarse tremor and hyperreflexia with inducible ankle clonus bilaterally. Her extraocular movements were normal, with no nystagmus. There were no focal neurologic abnormalities. She had evidence of intravascular volume depletion with a low jugular venous pressure.

Investigations showed random blood glucose 7.6 (normal 3.87.7) $\mathrm{mmol} / \mathrm{L}$; sodium 146 (normal 135-145) mmol/L; potassium 4.0 (normal 3.2-5.0) mmol/L; creatinine 115 (normal 50-98) $\mu \mathrm{mol} / \mathrm{L}$ with an estimated glomerular filtration rate (eGFR), $46 \mathrm{~mL} /$ $\mathrm{min} / 1.73 \mathrm{~m}^{2}$ (normal renal function was documented 2 years previously with creatinine $89 \mu \mathrm{mol} / \mathrm{L}$ and eGFR $64 \mathrm{~mL} / \mathrm{min} / 1.73 \mathrm{~m}^{2}$ ). A 12-lead electrocardiogram showed normal sinus rhythm, precordial T-wave inversions and a prolonged QTc interval of $533 \mathrm{~ms}$ (Figure 1). No acute intracranial abnormality was seen on unenhanced computed tomography scan of the head. The patient's serum lithium level was $1.50 \mathrm{mmol} / \mathrm{L}$ (normal therapeutic range $0.50-1.20 \mathrm{mmol} / \mathrm{L}$ ). Because of our patient's neurologic symptoms, electrocardiogram findings and mildly elevated serum lithium level, we diagnosed chronic lithium toxicity.

We stopped the lithium and gave the patient isotonic intravenous fluids. After 48 hours, her serum lithium level decreased to $0.40 \mathrm{mmol} / \mathrm{L}$, but rebounded to $1.30 \mathrm{mmol} / \mathrm{L}$ on day 3 of admission despite ongoing administration of intravenous fluid. During this time, there was no improvement in the patient's mental status. We consulted the regional poison centre and the nephrology service, and initiated hemodialysis. After 8 hours of sustained low-efficiency hemodialysis, her level of consciousness improved and her serum lithium levels were undetectable.

\section{Key points}

- Lithium is a commonly used medication that has a narrow therapeutic index and may lead to important toxicity that can be acute, chronic, or acute on chronic.

- Serum lithium levels are only 1 factor to help guide diagnosis and management, and clinically important chronic toxicity can occur in patients with minimally elevated serum levels.

- Early involvement of the regional poison centre is important in helping to guide management, including the decision to begin hemodialysis.

- Lithium rebound may occur after hemodialysis; serum levels should be measured every 4 hours until at least 12 hours after cessation of hemodialysis, ensuring the decline in levels is persistent.

- The syndrome of irreversible lithium-effectuated neurotoxicity (SILENT) is an uncommon complication of lithium toxicity involving persistent and predominantly cerebellar dysfunction.

Levels were monitored for 48 hours and remained undetectable. She had good neurologic recovery over the course of her hospital stay. One week after admission, after we discontinued intravenous fluids, we noted that she had persistent hypernatremia, polyuria with urine output of $3 \mathrm{~L} / \mathrm{d}$ and dilute urine with urine osmolality $102 \mathrm{mmol} / \mathrm{kg}$. We gave her desmopressin without response. We diagnosed lithium-induced nephrogenic diabetes insipidus; in retrospect, this was the likely precipitant for her toxicity owing to intravascular volume depletion, which caused acute kidney injury and impaired lithium excretion. We initiated her on amiloride $10 \mathrm{mg}$ orally daily to treat the nephrogenic diabetes insipidus, and her serum osmolality, polyuria and sodium levels normalized. We consulted the psychiatry service and began treatment with valproic acid to manage her bipolar I disorder.

\section{Discussion}

In 2019 in the United States, 7085 toxic lithium exposures were documented. ${ }^{1}$ This refers to substantial exposures that may have resulted in a clinical outcome of at least moderate severity. ${ }^{1}$ Of these, $22 \%$ resulted in serious clinical consequences, including 4 deaths. ${ }^{1}$ Lithium has a narrow therapeutic index and a wide 
range of toxicities. It is an effective and widely prescribed therapy for bipolar disorder and is also used off label for other psychiatric disorders. ${ }^{2}$ It is available in both immediate-release and sustained-release preparations. ${ }^{2}$ The recommended therapeutic range varies with patient age, owing to age-related changes in renal function and increased prevalence of polypharmacy and drug interactions. ${ }^{2}$ Lithium is an inorganic monovalent cation with a small molecular weight of $7 \mathrm{Da} .^{3}$ It is rapidly absorbed, not protein bound, has a low volume of distribution between 0.6 and $0.9 \mathrm{~L} / \mathrm{kg}$, and is freely excreted unchanged via the kidneys. ${ }^{3}$

The clinical manifestations of lithium toxicity depend on whether the exposure is acute, chronic, or acute on chronic (Table 1).

\section{Acute lithium toxicity}

Acute lithium toxicity refers to the ingestion of lithium by a patient who is lithium naive, without any pre-existing tissue burden. ${ }^{4}$ This typically occurs in the context of overdose. ${ }^{4}$ In acute toxicity, gastrointestinal symptoms are prominent, including nausea, vomiting, and diarrhea. ${ }^{3}$ Although neurologic symptoms may occur, they are often mild or delayed because distribution into the brain can take up to 24 hours after ingestion. ${ }^{3}$ Electrocardiographic abnormalities may be seen, including $\mathrm{T}$-wave inversion, QT interval prolongation, ST segment depression and bradycardia, although substantial cardiac toxicity is uncommon. ${ }^{3}$ Acute lithium toxicity has also been associated with serotonin syndrome. ${ }^{5}$

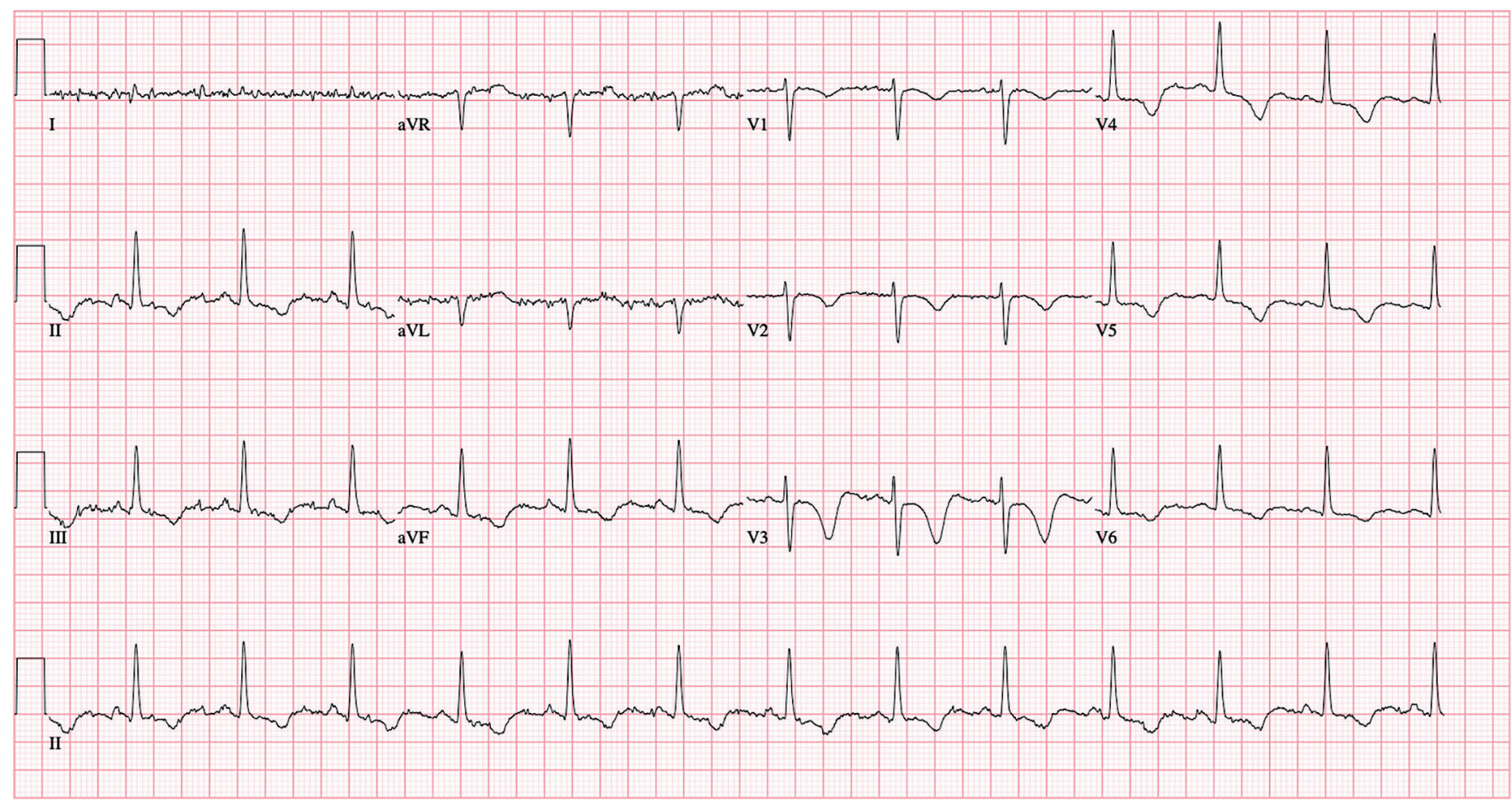

Figure 1: Electrocardiogram of a 54-year-old woman with chronic lithium toxicity, showing normal sinus rhythm, precordial T-wave inversions, and a prolonged QTc interval of $533 \mathrm{~ms}$.

\section{Table 1: Clinical features of lithium toxicity}

Pattern of exposure

Acute

Chronic

Acute-on-chronic

Any

\section{Clinical features}

- Gastrointestinal: nausea, vomiting, diarrhea

- Neurologic: mild and delayed

- Neurologic: tremor, hyperreflexia, myoclonus, weakness, ataxia, rigidity, dysarthria, nystagmus, altered level of consciousness, seizures

- Renal: nephrogenic diabetes insipidus, chronic tubulointerstitial nephropathy

- Endocrine: hypothyroidism, hyperthyroidism, hyperparathyroidism, hypercalcemia

- Syndrome of irreversible lithium-effectuated neurotoxicity (SILENT)

- Features of both acute and chronic toxicity

- Prominent gastrointestinal and neurologic manifestations

- Cardiac: electrocardiogram changes (T-wave inversions, QT prolongation, ST segment depression, sinus node dysfunction, bradycardia), rarely dysrhythmias 


\section{Chronic lithium toxicity}

Chronic toxicity occurs in patients maintained on lithium who have an established tissue burden, and then develop a condition that impairs renal lithium elimination by reducing glomerular filttration or increasing proximal tubule reabsorption. ${ }^{4}$ Common risk factors include volume depletion and concomitant use of nephrotoxic medications. ${ }^{4}$ In chronic toxicity, the manifestations are largely neurologic, including tremor, hyperreflexia, myoclonus, ataxia and nystagmus. ${ }^{3} \mathrm{~A}$ spectrum of alteration in mental status may occur, ranging from agitation and confusion to coma and seizures. ${ }^{3}$ Renal complications include chronic tubulointerstitial nephropathy and nephrogenic diabetes insipidus. ${ }^{6}$ Nephrogenic diabetes insipidus is common among those on chronic lithium therapy and can lead to intravascular volume depletion and acute kidney injury, predisposing patients to accumulation of lithium, as was suspected in our patient. ${ }^{6}$ Electrocardiographic abnormalities may also be seen in chronic toxicity. ${ }^{3}$

\section{Acute-on-chronic lithium toxicity}

Acute-on-chronic toxicity refers to the ingestion of lithium beyond the patient's maintenance dose. ${ }^{4}$ In acute-on-chronic toxicity, patients may have mixed clinical features, including prominent neurologic and gastrointestinal symptoms. ${ }^{3}$

\section{Management of lithium toxicity}

Serum lithium concentrations do not reliably correlate with the clinical severity of toxicity. ${ }^{3}$ Our patient had severe lithium toxicity with a minimally elevated serum level. This is often seen in chronic lithium toxicity owing to pre-existing lithium accumulation in the brain and peripheral tissues. ${ }^{3}$ Mild acute illness resulting in changes in renal function can create conditions for chronic toxicity in patients being treated with lithium. ${ }^{4}$ Therefore, regardless of the serum lithium level, clinicians should maintain a high degree of suspicion for chronic lithium toxicity with any clinical change in a patient on long-term lithium therapy.

The management of lithium toxicity involves supportive care, specifically protecting the airway if the patient has altered mental status, discontinuation of lithium exposure and enhancement of renal elimination. ${ }^{4}$ Early involvement of the regional poison centre is important to help guide management. There is no antidote to lithium toxicity. Although there is no role for activated charcoal, as it does not adsorb lithium, clinicians may consider whole-bowel irrigation, particularly in patients who have ingested sustained-release preparations, provided there are no contraindications. ${ }^{3}$

The most important component of management is isotonic intravenous fluid administration to improve the GFR and facilitate renal elimination. ${ }^{4}$ Failing this, extracorporeal treatment with hemodialysis is highly effective at removing lithium owing to its pharmacokinetic properties, including its small molecular weight and low volume of distribution. ${ }^{4}$ Although the question of when to offer hemodialysis to patients with lithium toxicity has been explored at length, the specific recommendations for its use vary substantially. This likely reflects the lack of strong evidence and the heterogeneity of the clinical presentation in patients with lithium toxicity. ${ }^{4,7}$ In general, the patient's clinical status, renal function and serum lithium concentration are considered when deciding whether hemodialysis should be offered. In 2015, the Extracorporeal Treatments in Poisoning Workgroup proposed a set of indications for hemodialysis in lithium toxicity, recognizing the limited available evidence (Table 2 ). ${ }^{8}$

Lithium rebound refers to a phenomenon in which serum lithium concentrations increase after initially decreasing. ${ }^{8}$ This occurs most commonly after cessation of intermittent hemodialysis in patients being treated for chronic lithium toxicity. ${ }^{8}$ The blood compartment is rapidly cleared first as lithium is removed, owing to its low volume of distribution; however, transcellular shift and slow diffusion of lithium out of tissues can result in a rebound phenomenon. ${ }^{9}$ Lithium rebound may also occur when a sustained-release preparation has been ingested because of ongoing absorption. ${ }^{9}$ In our case, lithium rebound was observed after treatment with intravenous fluid resuscitation alone, before the patient underwent hemodialysis. It is important to ensure that serum lithium levels are consistently decreasing or undetectable before determining that no further treatment is required. For this reason, it is recommended that levels be measured every 4 hours until at least 12 hours after cessation of hemodialysis. ${ }^{8}$

Finally, an important complication of lithium poisoning is prolonged neurologic dysfunction. ${ }^{4}$ The syndrome of irreversible lithium-effectuated neurotoxicity (SILENT) is characterized by persistent neurologic changes despite withdrawal of lithium therapy for at least 2 months. ${ }^{10}$ The manifestations of SILENT are largely cerebellar and may include tremor, nystagmus and dysarthria, among others. ${ }^{10}$ It remains unclear whether early or aggressive hemodialysis prevents SILENT, and what specific risk factors predispose to this condition. ${ }^{10}$

Table 2: Extracorporeal Treatments in Poisoning Workgroup indications for hemodialysis in lithium toxicity ${ }^{8}$

\begin{tabular}{llll}
\hline Indication & $\begin{array}{c}\text { Strength of } \\
\text { recommendation }\end{array}$ & Serum lithium concentration & \multicolumn{1}{c}{ Clinical features } \\
\hline $\begin{array}{l}\text { Hemodialysis } \\
\text { initiation }\end{array}$ & Recommended & $>4.0 \mathrm{mmol} / \mathrm{L}$ with abnormal GFR & $\begin{array}{l}\text { Decreased level of consciousness, seizures or life-threatening } \\
\text { dysrhythmias }\end{array}$ \\
\hline $\begin{array}{l}\text { Hemodialysis } \\
\text { cessation }\end{array}$ & Suggested & $>5.0 \mathrm{mmol} / \mathrm{L}$ & $\begin{array}{l}\text { Confusion, or lithium level not expected to fall to }<1.0 \mathrm{mmol} / \mathrm{L} \\
\text { within } 36 \mathrm{~h} \text { with optimal management }\end{array}$ \\
\hline Note: GFR = glomerular filtration rate. & $<1.0 \mathrm{mmol} / \mathrm{L}$ & $\begin{array}{l}\text { Clinical improvement apparent (minimum } 6 \mathrm{~h} \text { of hemodialysis if } \\
\text { serum lithium levels not available) }\end{array}$ \\
\hline
\end{tabular}


Lithium is a commonly prescribed medication with a narrow therapeutic index and may cause acute, chronic and acute-onchronic toxicity. The diagnosis of lithium toxicity should not rely solely on serum levels. Treatment is largely supportive, with attention to optimizing renal elimination, although hemodialysis may be indicated. Our patient required treatment with hemodialysis despite aggressive fluid resuscitation. She subsequently recovered and has remained well since discharge from hospital.

\section{References}

1. Gummin DD, Mowry JB, Beuhler MC, et al. 2019 annual report of the American Association of Poison Control Centers' National Poison Data System (NPDS): 37th annual report. Clin Toxicol (Phila) 2020;58:1360-541.

2. Yatham LN, Kennedy SH, Parikh SV, et al. Canadian Network for Mood and Anxiety Treatments (CANMAT) and International Society for Bipolar Disorders (ISBD) 2018 guidelines for the management of patients with bipolar disorder. Bipolar Disord 2018;20:97-170.
3. Greller H. Lithium. In: Nelson LS, Howland MA, Lewin NA, editors. Goldfrank's toxicologic emergencies. 11th ed. New York: McGraw-Hill Education; 2019.

4. Baird-Gunning J, Lea-Henry T, Hoegberg LCG, et al. Lithium poisoning. $J$ Intensive Care Med 2017;32:249-63.

5. Boyer EW, Shannon M. The serotonin syndrome. N Engl J Med 2005;352: 1112-20.

6. Grünfeld J-P, Rossier BC. Lithium nephrotoxicity revisited. Nat Rev Nephrol 2009;5:270-6.

7. Lavonas EJ, Buchanan J. Hemodialysis for lithium poisoning. Cochrane Database Syst Rev 2015;(9):CD007951.

8. Decker BS, Goldfarb DS, Dargan PI, et al. Extracorporeal treatment for lithium poisoning: systematic review and recommendations from the EXTRIP workgroup. Clin J Am Soc Nephrol 2015;10:875-87.

9. Timmer RT, Sands JM. Lithium intoxication. J Am Soc Nephrol 1999;10: 666-74.

10. Adityanjee, Munshi KR, Thampy A. The syndrome of irreversible lithiumeffectuated neurotoxicity. Clin Neuropharmacol 2005;28:38-49.

\section{Competing interests: None declared.}

This article has been peer reviewed.

The authors have obtained patient consent.

Affiliations: Department of Medicine (Kobylianskii, Austin, Gold, Wu), University of Toronto; Ontario Poison Centre (Austin), Hospital for Sick Children; Division of Clinical Pharmacology \& Toxicology (Austin, Wu), University of Toronto; Division of General Internal Medicine (Gold, Wu), University Health Network/Sinai Health System, Toronto, Ont.

Contributors: Jane Kobylianskii contributed to the conception and design of the work, the acquisition of patient data, and drafted the manuscript. Emily Austin and Wayne Gold contributed to the interpretation of data for the work and critical revisions for important intellectual content.
Peter Wu contributed to the conception and design of the work, the interpretation of data for the work, and critical revisions for important intellectual content. All authors gave final approval of the version to be published and agreed to be accountable for all aspects of the work.

Content licence: This is an Open Access article distributed in accordance with the terms of the Creative Commons Attribution (CC BY-NC-ND 4.0) licence, which permits use, distribution and reproduction in any medium, provided that the original publication is properly cited, the use is noncommercial (i.e., research or educational use), and no modifications or adaptations are made. See: https://creativecommons.org/licenses/ by-nc-nd/4.0/

Correspondence to: Jane Kobylianskii, Jane.kobylianskii@mail.utoronto.ca 